Cite this: RSC Adv., 2017, 7, 13104

Received 23rd January 2017

Accepted 17th February 2017

DOI: $10.1039 / \mathrm{c} 7 \mathrm{ra01028a}$

rsc.li/rsc-advances

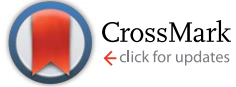

\section{Comparison of different silica microporous structures as drug delivery systems for in vitro models of solid tumors $\dagger$}

\author{
Natália Vilaça, ${ }^{a}$ Ana F. Machado, ${ }^{a}$ Filipa Morais-Santos, ${ }^{\text {bc }}$ Ricardo Amorim, ${ }^{\text {bc }}$ A. Patrícia \\ Neto, ${ }^{a}$ Enora Logodin, ${ }^{a}$ Manuel F. R. Pereira, ${ }^{d}$ Mariana Sardo, ${ }^{e}$ João Rocha, ${ }^{e}$ \\ Pier Parpot, ${ }^{a}$ António M. Fonseca, ${ }^{a}$ Fátima Baltazar ${ }^{\star b c}$ and Isabel C. Neves ${ }^{\star a}$
}

Several silica microporous structures have been studied for their potential as drug delivery systems (DDS) over the last years. However, systematic studies comparing host structures with different topologies and particle sizes, and toxicity studies to human cancer cells, are scarce. In the present work, 3D crystalline structures, three different zeolites (large, medium and small pore size) and one titanosilicate (large pore size) were used as hosts for loading 5-fluorouracil (5-FU), an anticancer drug currently used to treat several malignant tumors. Here, we (i) compared the loading capacity and drug release profiles of the different hosts in simulated body fluid conditions, including host structure stability studies; (ii) established the kinetic parameters for the release of 5-FU and (iii) studied the effect of 5-FU encapsulation in the viability of human breast and colon cancer cells, with determination of the potentiation factor. The loading capacity and the release profile of the DDS were revealed to be dependent on the porous framework of the host structures. Decrease in $\mathrm{pH}$ to 2.0 (simulation of gastro-intestinal fluid), showed stability of the host structures, with minimal leaching of $\mathrm{Al}^{3+}$ and no $\mathrm{Ti}^{4+}$ for long periods of time (up to 72 h). All DDS drug release profiles fitted the Weibull model. These silica microporous structures were revealed to be non-toxic to the cancer cells, while all DDS endorsed the important 5-FU potentiation effect on cell viability.

\section{Introduction}

The development and selection of drug delivery systems (DDS) is a field of vital importance in medicine and healthcare. The first commercial DDS was approved by FDA (U.S. Food and Drug Administration) in 1990, containing an antifungal drug, amphotericin $\mathrm{B}$, and after that more than 10 DDS became commercially available. ${ }^{1}$

An ideal DDS is a system that should improve drug bioavailability, prevent its premature degradation, also potentiating its effect. Importantly, the systems must maintain drug concentrations within their therapeutic window, by controlling

${ }^{a}$ Centre of Chemistry, Chemistry Department, University of Minho, Campus de Gualtar, 4710-057 Braga, Portugal.E-mail: ineves@quimica.uminho.pt

${ }^{b}$ Life and Health Sciences Research Institute (ICVS), School of Medicine, University of Minho, Campus Gualtar, Braga, Portugal.E-mail: fbaltazar@med.uminho.pt

'ICVS/3B's - PT Government Associate Laboratory, Guimarães, Braga, Portugal

${ }^{d}$ Laboratory of Catalysis and Materials (LCM), Associate Laboratory LSRE-LCM, Faculdade de Engenharia, University of Porto, Rua Dr Roberto Frias, 4200-465 Porto, Portugal

${ }^{e}$ CICECO - Chemistry Department, University of Aveiro, Campus de Santiago, 3810193 Aveiro, Portugal

† Electronic supplementary information (ESI) available. See DOI: 10.1039/c7ra01028a the drug release rates, and target the pharmacological site at effective concentrations, but with low cytotoxicity. ${ }^{\mathbf{1 , 2}}$

In this context, inorganic nanomaterials have a range of structural and physical properties that are suitable for therapeutic delivery systems. The sizes, topologies, and surfaces of inorganic nanomaterials can be tailored to produce distinct interactions with both in vitro and in vivo biological systems. ${ }^{3}$ In this class of materials, silica-based structures, such as microporous crystalline titanosilicates and zeolites, mesoporous silica and amorphous or/and crystalline silica particles, are important materials with a wide range of applications.

Thus, zeolites and titanosilicate materials are porous nanomaterials with many potential applications in the biomedical field. There are several examples of zeolite application reported in the literature, including for drug delivery ${ }^{4-6}$ and imaging. ${ }^{7-9}$ These examples show that different zeolite structures can be exchanged with cations, functionalized or loaded with drug molecules for specific biomedical applications. ${ }^{10}$ In the case of the microporous titanosilicate materials, recent studies show that these materials have potential as drug carriers, with low cytotoxicity. ${ }^{11-13}$

The goal of this work is to study the potential of several silica microporous structures as hosts for 5-fluorouracil (5-FU) as drug delivery systems for in vitro models of colorectal and breast 
cancers. 5-FU is a pyrimidine analog antimetabolite, with a general spectrum of activity against solid tumors, such as breast, colorectal, liver and brain cancer, alone or in combination with other chemotherapeutic agents. ${ }^{\mathbf{1 4 - 1 6}}$ Due to its structure, 5-FU interferes with nucleoside metabolism and can be incorporated into RNA and DNA, leading to cytotoxicity and tumor cell apoptosis, by inhibiting thymidylate synthase. ${ }^{\mathbf{1 4}}$ There are several limitations to the use of 5-FU, including its erratic oral bioavailability, with variable gastrointestinal absorption and rapid degradation, its short plasma half-life, development of resistance and important cytotoxicity to normal cells. ${ }^{15,17,18}$ Thus, preparation of DDS containing 5-FU could improve its oral bioavailability, preventing its premature degradation and decrease its side effects, increasing concentrations at the target cell site, with lower cytotoxicity for normal cells.

\section{Experimental}

\section{Preparation and characterization of the silica microporous structures as host for the DDS}

Several powder silica microporous structures: three zeolites, FAU (NaY, Si/Al $=2.83$, CBV100, Zeolyst International); MFI $\left(\left(\mathrm{NH}_{4}\right) \mathrm{ZSM} 5, \mathrm{Si} / \mathrm{Al}=15.0, \mathrm{CBV} 3024 \mathrm{E}\right.$, Zeolyst International $)$ and Linde Type A (NaA, Si/Al = 1.24, BCR-705, Sigma-Aldrich), and one titanosilicate, Engelhard Titano Silicate (ETS-10) were used as host for preparing DDS with 5-fluoro-1 $H$-pyrimidine-2,4dione usually 5-fluorouracil (5-FU, Sigma-Aldrich, 99\%). ETS10 was synthesized according to the procedure previously published. ${ }^{19}$ The pentasil structure was subjected to the treatments used before in order to obtain NaZSM5. NaZSM5 was prepared by ion exchange of $\mathrm{NH}_{4}{ }^{+}$from $\left(\mathrm{NH}_{4}\right) \mathrm{ZSM} 5$ by $\mathrm{Na}^{+}$with $\mathrm{NaNO}_{3}$ solution. ${ }^{20}$ Briefly, sample was prepared by exchanging $5 \mathrm{~g}$ of $\left(\mathrm{NH}_{4}\right)$ ZSM5 with $125 \mathrm{~mL}$ (25 mL of solution per $\mathrm{g}$ zeolite) of $0.50 \mathrm{M} \mathrm{NaNO}_{3}$ solution in an Erlenmeyer flask with a stirrer at room temperature during $24 \mathrm{~h}$. The suspension was separated by filtration, washed with deionized water and dried in an oven at $60{ }^{\circ} \mathrm{C}$ for $8 \mathrm{~h}$. The same procedure was performed with a fresh $0.50 \mathrm{M} \mathrm{NaNO}_{3}$ solution. After the two ion exchange treatments, NaZSM5 was dried in an oven at $60{ }^{\circ} \mathrm{C}$ for $8 \mathrm{~h}$ and calcined at $500{ }^{\circ} \mathrm{C}$ during $8 \mathrm{~h}$ under a dry air stream.

The morphology and the particle size of the hosts were carried out by scanning electron microscopy (SEM) (JOEL JSM-6010LV/ Braga). Textural characterization of the hosts was based on the analysis of $\mathrm{N}_{2}$ adsorption isotherms, measured at $-196{ }^{\circ} \mathrm{C}$ with a Nova 4200e (Quantachrome Instruments) equipment.

\section{DDS preparation}

Before use, all powder silica microporous structures were dehydrated at $120{ }^{\circ} \mathrm{C}$ overnight in order to remove the water from the pores. All DDS were prepared by the established encapsulation method. ${ }^{\mathbf{4} 21}$ So, 5-FU was encapsulated into the host structures by mixing $100 \mathrm{mg}$ of each host with a solution of 5-FU (130 mg, $0.99 \mathrm{mmol})$ in acetone $(15 \mathrm{~mL}$, Aldrich P.A.) as a solvent and was stirred for $48 \mathrm{~h}$ at room temperature. The suspensions were filtered off and dried in an oven at $60{ }^{\circ} \mathrm{C}$ for
$24 \mathrm{~h}$. Finally, the resulting DDS were stored in a desiccator. The $\mathrm{pH}$ of the suspensions was monitored during the DDS preparation. Throughout the manuscript, the obtained DDS were identified to as 5-FU@porous where porous represents the silica host structure used in DDS.

The amount of loaded 5-FU was measured using thermogravimetric analysis (TGA) in a STA 409 PC/4/H Luxx Netzsch thermal analyzer. The atmosphere used was high purity air (99.99\% minimum purity) with a flow rate of $50 \mathrm{~cm}^{3} \mathrm{~min}^{-1}$. The sample holders used were crucibles of alumina oxide, supplied by Netzsch. The samples were heated between 50 and $700{ }^{\circ} \mathrm{C}$ at $10{ }^{\circ} \mathrm{C} \min ^{-1}$ to evaluate the thermal stability.

\section{Drug release studies of 5-FU@porous and stability of the hosts structures}

The drug release studies were performed according to the procedure describe elsewhere., ${ }^{\mathbf{4 , 2}}$ Briefly, the studies were carried out with $10 \mathrm{mg}$ of DDS mixed in $50 \mathrm{~mL}$ of specific solutions in order to mimic body fluid conditions (BF) at different pHs and $37^{\circ} \mathrm{C}: \mathrm{pH} 7.4$ obtained with a solution of $\mathrm{Na}_{2} \mathrm{HPO}_{4} / \mathrm{NaH}_{2} \mathrm{PO}_{4} ; \mathrm{pH} 5.8$ obtained with a solution of $\mathrm{KH}_{2} \mathrm{PO}_{4} / \mathrm{NaOH}$ and $\mathrm{pH} 2.0$ with a solution of $\mathrm{KCl} / \mathrm{HCl}$. The samples were stirred at ca. $60 \mathrm{rpm}$ and $5 \mathrm{~mL}$ aliquots of DDS/ BF solution were removed at regular intervals and an equal amount of fresh dissolution medium was added to keep the volume of the mixture constant $(50 \mathrm{~mL})$. Aliquots were filtered through a $0.20 \mu \mathrm{m}$ filter (Whatman). Quantification of the release of 5-FU was carried out by UV/vis spectroscopy using a UV-vis Recording Spectrophotometer UV-250 1PC from Shimadzu with software UVProbe 2.10. From the withdrawn aliquots, $0.5 \mathrm{~mL}$ were placed in quartz cuvette and added to $2.5 \mathrm{~mL}$ of each BF solution and the absorbance of 5 -FU was monitored at $260 \mathrm{~nm}$. From the withdraw aliquots, $0.5 \mathrm{~mL}$ of this solution was placed in quartz cuvette and added with 2.5 $\mathrm{mL}$ of each BF solution and the absorbance of 5-FU was monitored at $260 \mathrm{~nm}$. A calibration curve was constructed using solutions of 5-FU with concentrations from 0.0005 to $0.1000 \mathrm{mg} \mathrm{mL}^{-1}$. The amount of released 5 -FU was calculated using the equation previously described. ${ }^{\mathbf{4 , 2 3}}$ Experiments were conducted in triplicate and the values were averaged. The release studies were carried out for $6 \mathrm{~h}$.

The stability of the host structures was evaluated by FTIR and XRD analyses. In these studies, $15 \mathrm{~mL}$ of $\mathrm{pH} 2.0 \mathrm{BF}$ solution was added to $10 \mathrm{mg}$ of NaY or ETS-10 during $72 \mathrm{~h}$ under stirring at room temperature. The suspensions were filtered off and dried in an oven at $60{ }^{\circ} \mathrm{C}$ for $24 \mathrm{~h}$, and stored in a desiccator. The $\mathrm{pH}$ of the suspensions was monitored during the assay. Room temperature Fourier Transform Infrared (FTIR) spectra of the parent structures in $\mathrm{KBr}$ pellets $(2 / 100 \mathrm{mg}$ ) were measured using a ABB FTLA2000 spectrometer in the range $4000-500 \mathrm{~cm}^{-1}$ by averaging 32 scans at a maximum resolution of $8 \mathrm{~cm}^{-1}$. Powder $\mathrm{X}$-ray diffraction analysis (XRD) was carried out using a Philips Analytical X-ray model PW1710 BASED diffractometer system equipped with a $\mathrm{Cu}$ X-ray tube (selected wavelength $\lambda_{\mathrm{CuK} \alpha}=$ $1.54056 \AA$ ). Scans were taken at room temperature in a $2 \theta$ range between 5 and $70^{\circ}$ with a step of $0.02^{\circ}$. 


\section{Cell viability studies}

The cell viability studies were performed with two human colon cancer cell lines and one breast cancer cell line. The human breast cancer cell line, MDA-MB-468, was obtained from ATCC (American Type Culture Collection). The human colon cancerderived cell lines HCT-15 and RKO were kindly provided by Dr Raquel Seruca (IPATIMUP, Porto, Portugal). HCT-15 colon cancer cells were maintained in RPMI 1640 medium (Gibco), RKO colon cancer cells and MDA-MB-468 breast cancer cells were maintained in DMEM medium (Gibco). Both cell lines were supplemented with $10 \%(\mathrm{v} / \mathrm{v})$ fetal bovine serum (FBS) (Gibco, Invitrogen, USA) and $1 \%(\mathrm{v} / \mathrm{v})$ penicillin-streptomycin solution $(\mathrm{P} / \mathrm{S})$ (Invitrogen, USA) and incubated at $37{ }^{\circ} \mathrm{C}$ in a $5 \%$ $\mathrm{CO}_{2}$ humidified atmosphere. Cells were subcultured approximately every three days and maintained in a log-phase growth.

Cell viability was assessed using the in vitro Toxicology Assay Kit. Sulforhodamine B (SRB) based (Sigma-Aldrich, St. Louis, MO, USA). HCT-15 (7500 cells per $100 \mu \mathrm{L}$ per well), RKO (6000 cells per $100 \mu \mathrm{L}$ per well) and MDA-MB-468 (10 000 cells per 100 $\mu \mathrm{L}$ per well) cells were seeded in 96-well plates and incubated at $37{ }^{\circ} \mathrm{C}$ in a $5 \% \mathrm{CO}_{2}$ humidified atmosphere for $24 \mathrm{~h}$. In order to assess the effects of the parent structures, 5-FU and DDS used and cells were incubated with increasing concentrations of the systems in culture medium. Controls were performed with culture medium alone. After an incubation period of $48 \mathrm{~h}$, the spent media were removed and the plate wells were washed with $1 \times$ phosphate-buffered solution, pH 7.4 (PBS). After a fixation step with cold $10 \%$ trichloroacetic acid (TCA), cells were stained with $0.4 \%$ SRB and the incorporated dye was solubilized with $10 \mathrm{mM}$ of Tris. Absorbance was monitored with a microplate reader at $570 \mathrm{~nm}$ with a background absorbance of $655 \mathrm{~nm}$. Cell viability was determined as percentage of viability: (OD experiment/OD control) $\times 100(\%)$. One-way ANOVA, followed by Dunnett post-test were used to perform cell viability assay statistical analysis. The previous tests and 50\% growth inhibition $\left(\mathrm{IC}_{50}\right)$ were determined using the Graphpad Prism $5{ }^{\circledR}$ software. The level of significance in all the statistical analysis was set at $* * * p<0.001$ compared to host alone. All assays were performed in triplicate from three independent experiments. The results were expressed as mean value \pm SD of the triplicate assays.

\section{Results and discussion}

DDS were prepared using silica microporous structure hosts with different topologies and pore sizes, containing aluminum or titanium in the framework.

The chosen 3D zeolites belong to the FAU (large pores), MFI (medium pores) and LTA (small pores) structures. ${ }^{24}$ ETS-10 is a 3D large pore structure with titanium in the framework. ${ }^{11}$ The hosts NaY (FAU) and NaA (LTA) were commercially available. However, the parent ETS-10 structure was synthesized and the parent $\left(\mathrm{NH}_{4}\right)$ ZSM5 (MFI) was modified in order to obtain HZSM5 and NaZSM5. The modifications in ZSM5 host were performed to study the pore aperture effect in the loading of 5FU. NaY was already used in a previous publication to encapsulate 5-FU and it is used here for comparison with the remaining structures. ${ }^{4}$

SEM and nitrogen adsorption analyses were performed for evaluating the average particle size and the surface area of the hosts, respectively. Fig. 1 display the SEM micrographs of some silica microporous structures. The average of the particle size obeys the following sequence, larger particles (>100 nm): NaY $700 \mathrm{~nm},{ }^{4}$ ZSM5 $880 \mathrm{~nm}, \mathrm{NaA} 2700 \mathrm{~nm}$ and ETS-10 with $2600 \mathrm{~nm}$ and smaller particles (<100 nm): LTL $80 \mathrm{~nm} .^{4}$

The nitrogen adsorption measurements show different surface areas for the zeolite hosts. The BET surface areas $\left(S_{\mathrm{BET}}\right)$ was determined by the BET equation and the values obtained were: NaY $792 \mathrm{~m}^{2} \mathrm{~g}^{-1}$, LTL $566 \mathrm{~m}^{2} \mathrm{~g}^{-1}$, ZSM5 $395 \mathrm{~m}^{2} \mathrm{~g}^{-1}$ and NaA $290 \mathrm{~m}^{2} \mathrm{~g}^{-1}$.

The 5-FU release studies were carried out with all DDS at different $\mathrm{pH}$ media simulating blood and gastrointestinal body fluids, ${ }^{25}$ and the stability of the host structure at $\mathrm{pH}=2.0$ was studied with NaY and ETS-10. Besides, cell viability studies were performed on HCT-15 and RKO human colon cancer cells for all hosts and DDS. However, the viability on MDA-MB-468 human breast cancer cell was tested only with the DDS based in NaY, ETS-10 (large pores) and compared with $\mathrm{NaA}$ (small pores).

Table 1 shows the loading of 5-FU in the silica microporous structures obtained by thermogravimetric analysis. TGA profile results are similar for all DDS with two weight losses observed; the first weight loss was related to the removal of physisorbed water of the host structure and the other one was attributed to the presence of 5 -FU in the DDS. ${ }^{4}$ The presence of acetone was not detected by TGA analysis since the temperature used in the preparation of the DDS is sufficient to evaporate the solvent. ${ }^{26}$

It is evident that loading of 5-FU in the DDS is related to the porous framework of the hosts. The large pore structures, NaY and ETS-10, have higher 5-FU loading capacity than the remaining microporous structures. The medium pore structure HZSM5 presents intermediate 5-FU loading and the introduction of sodium in $\left(\mathrm{NH}_{4}\right) \mathrm{ZSM} 5$ by ion exchange, enhances a decrease in the loading of 5-FU with $6.8 \mathrm{mmol}$ per $\mathrm{g}_{\text {host }}$ for
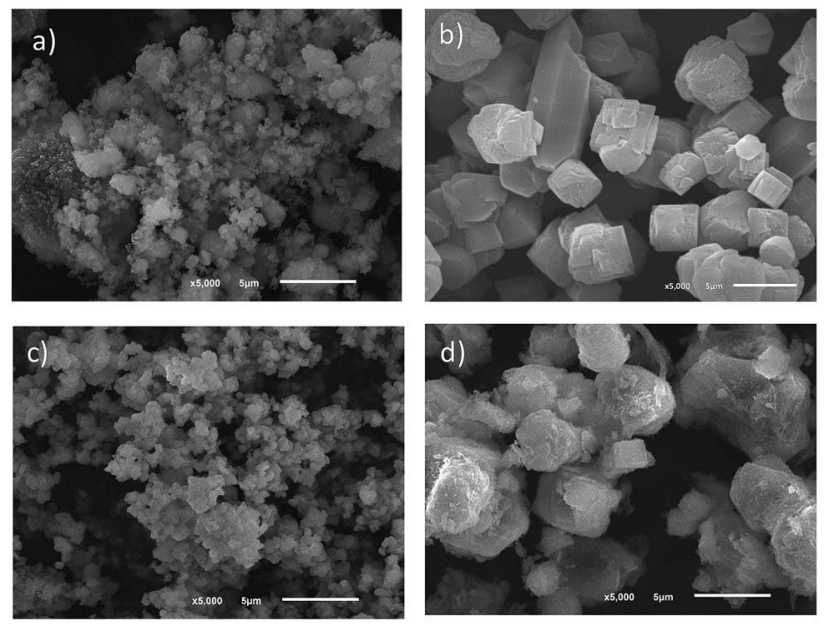

Fig. 1 SEM micrographs of (a) ZSM5, (b) ETS-10, (c) NaY and (d) NaA with same resolution. 
Table 1 Loading of 5-FU in DDS

\begin{tabular}{lllll}
\hline Host & DDS & $R_{\text {Theo. }}{ }^{a}$ & $R_{\text {Exp. }}{ }^{a}$ & 5-FU \\
\hline NaY & 5-FU@NaY & 1.30 & 0.98 & 7.5 \\
HZSM5 & 5-FU@HZSM5 & 1.30 & 0.97 & 7.4 \\
NaZSM5 & 5-FU@NaZSM5 & 1.30 & 0.89 & 6.8 \\
NaA & 5-FU@NaA & 1.30 & 0.75 & 5.8 \\
ETS-10 & 5-FU@ETS-10 & 1.30 & 0.99 & 7.6
\end{tabular}

${ }^{a} R_{\text {Theo. }}$ and $R_{\text {Exp. }}$ is the ratio of [5-FU]/[host] (wt/wt). ${ }^{b} 5$-FU loading in host determined by TGA.

NaZSM5, followed by the small pore structure NaA (3D) with $5.8 \mathrm{mmol}$ per $\mathrm{g}_{\text {host }}$.

In order to mimic the in vitro conditions of the cancer cell viability assays, 5-FU release studies from the silica microporous structures were performed in culture medium at different $\mathrm{pH}$ values and $37{ }^{\circ} \mathrm{C}$, by $\mathrm{UV} / \mathrm{vis}$ analysis. The release was recorded for $360 \mathrm{~min}$, however the concentration remained constant after $60 \mathrm{~min}$.

These studies have been conducted at $\mathrm{pH} 7.4,5.8$ and 2.0 in order to simulate the blood, intestinal and stomach fluids, respectively. ${ }^{25}$ As expected, 5-FU can be easily released from the different microporous hosts due to its small size. ${ }^{4}$ As an example, the UV/vis spectra of 5-FU release from 5-FU@NaY (Fig. S1, ESI $\dagger$ ) and the release profiles versus time at $\mathrm{pH} 7.4$ of the prepared DDS are shown in Fig. 2.

The results from UV/vis spectra show that, after release from the DDS, 5-FU molecule maintain the characteristic wavelength of the drug $(\lambda=260 \mathrm{~nm}) .{ }^{27}$ All DDS release profiles show similar behavior, with almost complete release of the adsorbed 5-FU after $40 \mathrm{~min}$, as a consequence of the rapid desorption of the drug.

The cumulative concentrations for all DDS stabilize after this time and display approximately the same value until the end of the dissolution assays (360 $\mathrm{min})$. However, some differences were observed between ETS-10 and the zeolites. The release of 5FU appears to be dependent on the 5-FU loading capacity of the host. From the large pore 3D structures, ETS-10 and NaY display

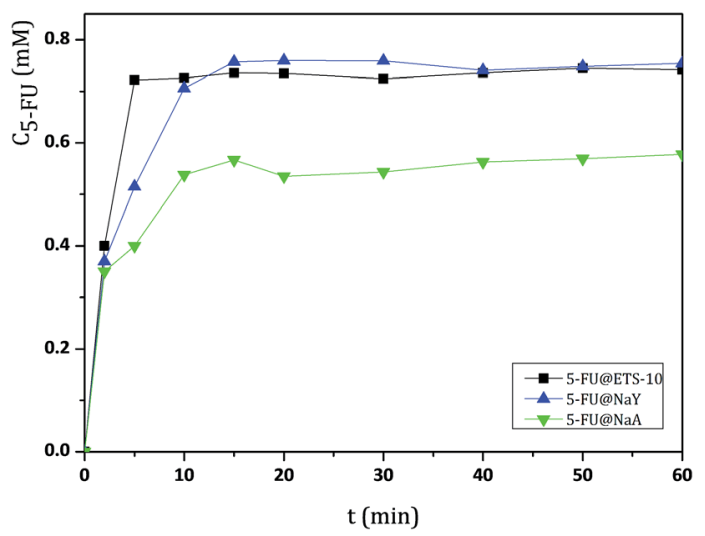

Fig. 2 Release profiles of DDS obtained in $\mathrm{BF}$ solution at $\mathrm{pH}=7.4$ and $37{ }^{\circ} \mathrm{C}$, followed during $60 \mathrm{~min}$. Release measurements were conducted in triplicate and the concentration values were averaged. the highest 5-FU release rates due to the higher amount of adsorbed drug, being ETS-10 release slightly faster (Table 1). The DDS based on NaA show the slowest rates compared to the large pore structures. The same behavior was observed for HZSM5 and NaZSM5, with the last one presenting the lowest release rates due to the introduction of sodium in the structure (Fig. 3).

These results are in line with those reported in the literature, which show that silica materials are an important class of controlled release matrices.

In the work of Larsen et al. the effect of different $\mathrm{Si} / \mathrm{Al}$ ratio of $\mathrm{Y}$ zeolite as hosts for loading and release of 5-fluorouracil were studied and they observed a similar behavior. ${ }^{28}$ Also, the DDS based on mesoporous organo-silica nanoparticles with different drugs present the same profile of drug release ${ }^{29}$ and the mesoporous silica material SBA-15 was used to achieve immediate release of poorly soluble drug compounds such as itraconazole. ${ }^{30}$ However, the studies stated by Martens et al. show that the release of the antiseptic chlorhexidine, a large molecule with antibacterial activity, from amorphous microporous silica was fine-tuned by adapting particle size and pore diameter. ${ }^{31}$ Recently, our group also showed that the release of salicylic acid from mesoporous and microporous silica hosts is dependent of the pore size of the carriers. ${ }^{26}$

There are several mathematical kinetic models used to describe in vitro drug dissolution and drug release from particles. $^{32-34}$ Weibull, first-order, Higuchi and Korsmeyer-Peppas are some of the major applied and best describing drug release models. ${ }^{32-34}$ The release profiles at $\mathrm{pH} 7.4$ were fitted to these models and the Weibull model shows the best fitting (Fig. S2, $\mathrm{ESI} \dagger)$. In this kinetic model two parameters were determined, the shape (" $b$ ") and scale (" $a$ ") parameters. The " $b$ " parameter describe the shape of the dissolution curve and the " $a$ " parameter represents the time dependence of the system. ${ }^{32-34}$ These parameters obtained with this model are listed in Table 2.

The " $b$ " parameter calculated for all DDS seems to be dependent on the microporous structures of the hosts. The large pore structures, NaY and ETS-10, have the highest values

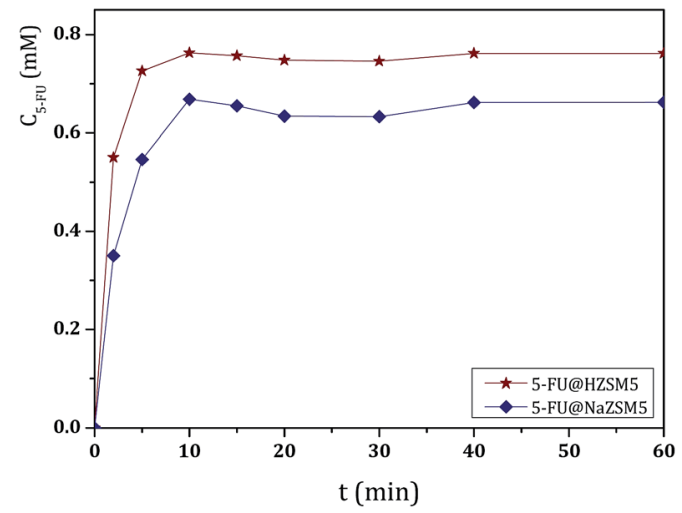

Fig. 3 Release profiles of 5-FU@HZSM5 and 5-FU@NaZSM5 obtained in $\mathrm{BF}$ solution at $\mathrm{pH}=7.4$ and $37^{\circ} \mathrm{C}$, followed during $60 \mathrm{~min}$. Release measurements were conducted in triplicate and the concentration values were averaged. 
Table 2 Fitted kinetic parameters for the release of 5-FU from DDS according to the Weibull model

\begin{tabular}{llll}
\hline DDS & “ $b{ }^{a}$ & “a ${ }^{a}$ & $R^{b}$ \\
\hline 5-FU@NaY & 0.35 & 0.08 & 0.9986 \\
5-FU@HZSM5 & 0.21 & 0.49 & 0.9996 \\
5-FU@NaZSM5 & 0.26 & 0.65 & 0.9975 \\
5-FU@NaA & 0.15 & 0.41 & 0.9699 \\
5-FU@ETS-10 & 0.40 & 0.16 & 0.9842
\end{tabular}

$a$ " $b$ " is the shape parameter and " $a$ " is the scale parameter of the Weibull model. ${ }^{32} b$ Correlation coefficient.

with 0.35 and 0.40 , respectively; followed by the medium pores with similar values and the small pores with 0.15 . This parameter describes the shape of the curve as exponential $(b=$ 1 , case 1$)$, sigmoid, S-shaped, $(b>1$, case 2$)$, or parabolic, with a higher initial slope and after that consistent with the exponential ( $b<1$, case 3$){ }^{32-34}$ The obtained values are in accordance to case 3 where the release profiles of all DDS present in Fig. 2 and 3 show this behavior.

The effect of $\mathrm{pH}$ on drug release was also evaluated at $\mathrm{pH} 5.8$ and 2.0. The lower $\mathrm{pH}$ medium is more likely to affect the stability of the DDS since 5-FU is a weak acid (pKa of 7.93) and the $\mathrm{pH}$ influences the interaction of the molecule with the surface. ${ }^{27}$ For these studies, all DDS were submitted to these different $\mathrm{pH}$ media, and Fig. 4 shows the results obtained for 5FU@NaA, as an example.

As expected from 5-FU structure, even at low $\mathrm{pH}$, the 5-FU molecule is not degraded since, we did not observe any shift of the characteristic wavelength of the drug. The results show that the variation of $\mathrm{pH}$ does not affect the release of 5-FU in the $\mathrm{pH}$ range of 2.0 to 7.4. The effect of $\mathrm{pH}$ was also studied for evaluation of the stability of the host microporous structures since the host is important in the protection of the drug in the DDS.

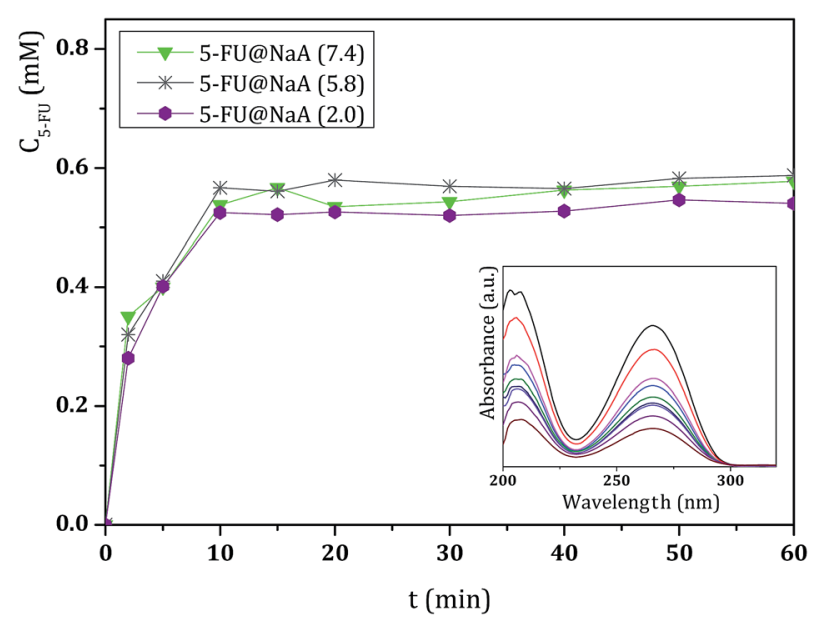

Fig. 4 Release profiles of 5-FU@NaA DDS obtained in different BF solutions at $\mathrm{pH}=7.4,5.8$ and 2.0 and $37^{\circ} \mathrm{C}$, followed during $60 \mathrm{~min}$. Release measurements were conducted in triplicate and the concentration values were averaged. (Inset) UV/vis spectra up to $60 \mathrm{~min}$ of the release of $5-\mathrm{FU}$ from the DDS at $\mathrm{pH}=2.0$.
For this study, the large pore structures NaY and ETS-10 were selected and tested at lower $\mathrm{pH}$. Besides, we also aimed to check if there was any leaching of $\mathrm{Al}^{3+}$ from NaY or $\mathrm{Ti}^{4+}$ from ETS-10. These hosts were incubated to $\mathrm{pH}$ 2.0 BF solution for $72 \mathrm{~h}$ under stirring, at room temperature. After the filtration and drying steps, the resulting solids were analyzed by FTIR and XRD. Fig. 5 displays the FTIR spectra obtained before and after $\mathrm{NaY}$ and ETS-10 treatment, respectively.

FTIR spectra obtained after treatment for both host structures show the fingerprint bands of the parent structures. ${ }^{35,36}$ Also, the principal vibrational bands of the host structures after treatment do not shift or broaden, which confirms that the pore frameworks remain unchanged. So, in all FTIR spectra, a very intense broad band at $c a .3500 \mathrm{~cm}^{-1}$ attributed to the hydroxyl groups, the $\nu(\mathrm{O}-\mathrm{H})$ deformation band at $1650 \mathrm{~cm}^{-1}$ characteristic of the absorbed water and in the spectral region between 1250 and $500 \mathrm{~cm}^{-1}$, the bands corresponding to the lattice vibrations of the structures are observed. ${ }^{35,36}$

In the case of NaY zeolite, FTIR analysis allows to determine the framework $\mathrm{Si} / \mathrm{Al}$ ratio using the characteristic band of the zeolite specific double ring vibration mode between 570-600 $\mathrm{cm}^{-1} \cdot{ }^{37}$ From both spectra in Fig. $5 \mathrm{a}$, bands at $577.1 \mathrm{~cm}^{-1}$ and $577.7 \mathrm{~cm}^{-1}$ for $\mathrm{NaY}$ and $\mathrm{NaY}(\mathrm{pH}=2.0)$ were identified,
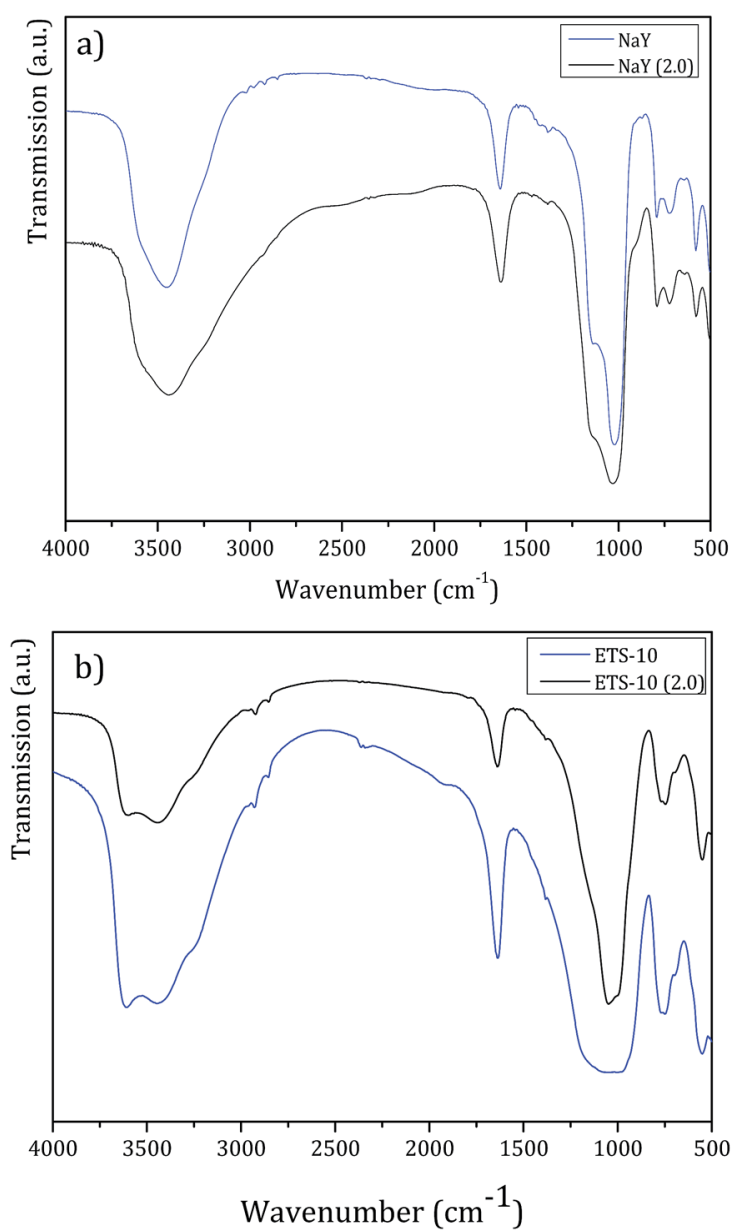

Fig. 5 FTIR spectra before and after treatment with $\mathrm{pH}=2.0 \mathrm{BF}$ solution of (a) NaY and (b) ETS-10, for $72 \mathrm{~h}$. 


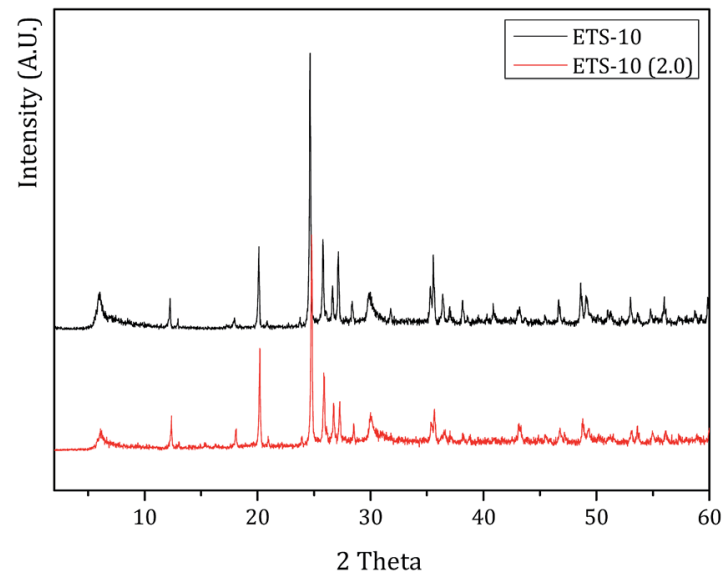

Fig. $6 \mathrm{XRD}$ patterns before and after treatment with $\mathrm{pH}=2.0 \mathrm{BF}$ solution of ETS-10 for $72 \mathrm{~h}$.

respectively. From these values, the calculated framework Si/Al ratio was 2.66 for $\mathrm{NaY}$ and 2.71 for $\mathrm{NaY}(\mathrm{pH}=2.0)$. The increase in $\mathrm{Si} / \mathrm{Al}$ ratio observed is related to partial desalumination due to the contact of the zeolite structure with the lower $\mathrm{pH}$ solution.

XRD analysis confirms these results. The powder X-ray diffraction patterns endorses that the crystalline structure of NaY or ETS-10 does not change after the treatment. In both XRD patterns after treatment, the characteristic Miller peaks corresponding to NaY or ETS-10 were observed indicating that the host structures are not severely affected by low $\mathrm{pH}(\mathrm{pH} 2.0)$. Fig. 6 displays the XRD patterns of ETS-10 and ETS- 10 at $\mathrm{pH}=$ 2.0. From Fig. 6, the XRD patterns of both samples ETS-10 and ETS-10 (2.0) are similar and in good accordance with those reported in the literature..$^{38,39}$

The relative crystallinity was estimated by the intensity of the characteristic diffraction peaks of the host structures after treatment, compared to the pattern of the parent structures, which was set to be $100 \%$ crystalline. The crystallinity obtained was $100 \%$ for ETS-10 $(\mathrm{pH}=2.0)$ and $85 \%$ for $\mathrm{NaY}(\mathrm{pH}=2.0)$.
These results confirm that ETS-10 is not affected by $\mathrm{pH} 2.0$ and $\mathrm{NaY}$ is slight affected by the treatment, which is in agreement with the FTIR results.

\section{Cell viability studies}

Cell viability assays were performed with all parent silica microporous to compare their feasibility as host for DDS using different human cell lines, RKO and HCT-15 as colon cancer models and MDA-MB-468 as breast cancer model. These cell lines represent important human carcinomas and they were chosen as extrapolative models to test the potentiation of the chemotherapeutic agent 5-FU when encapsulated in the silica microporous structures. The large pore structures, NaY and ETS-10, and the corresponding DDS were used and compared with the small pore structure $\mathrm{NaA}$ in the viability study with the human cell line MDA-MB-468, as breast cancer model.

The viability assays with microporous structures were optimized in our previous work. ${ }^{26}$ So, from a stock suspension (1.0 mg DDS per $\mathrm{mL}$ ), sequential dilutions were made with free serum culture medium in order to get several working DDS concentrations $\left(0.005\right.$ to $\left.0.100 \mathrm{mg} \mathrm{mL}^{-1}\right)$. The alterations in cell biomass were evaluated by the sulforhodamine B (SRB) method and were assessed after $48 \mathrm{~h}$ of incubation with DDS and the parent hosts.

The parent hosts did not induce reduction in cell viability in any of the cell lines studied. As an example, the ability of 5-FU released from 5-FU@ETS-10 and 5-FU@NaA to affect RKO cell viability is shown in Fig. 7. The other DDS cell viability are shown in Fig. S3 (ESI $\dagger$ ).

The hosts titanosilicate (ETS-10) and NaA do not show cytotoxicity to the colorectal cancer cell lines studied. The results are in accordance with what we have found for in the DDS prepared with different zeolite structures as hosts with the anticancer drugs $\alpha$-cyano-4-hydroxycinnamic acid (CHC) and 5fluorouracil (5-FU), and we also studied their in vitro efficacy against colorectal carcinoma cells. ${ }^{\mathbf{4 , 2 6 , 4 0}}$ These results are also in line with several toxicity studies which suggest that the internal surface of zeolites does not interact with the biological
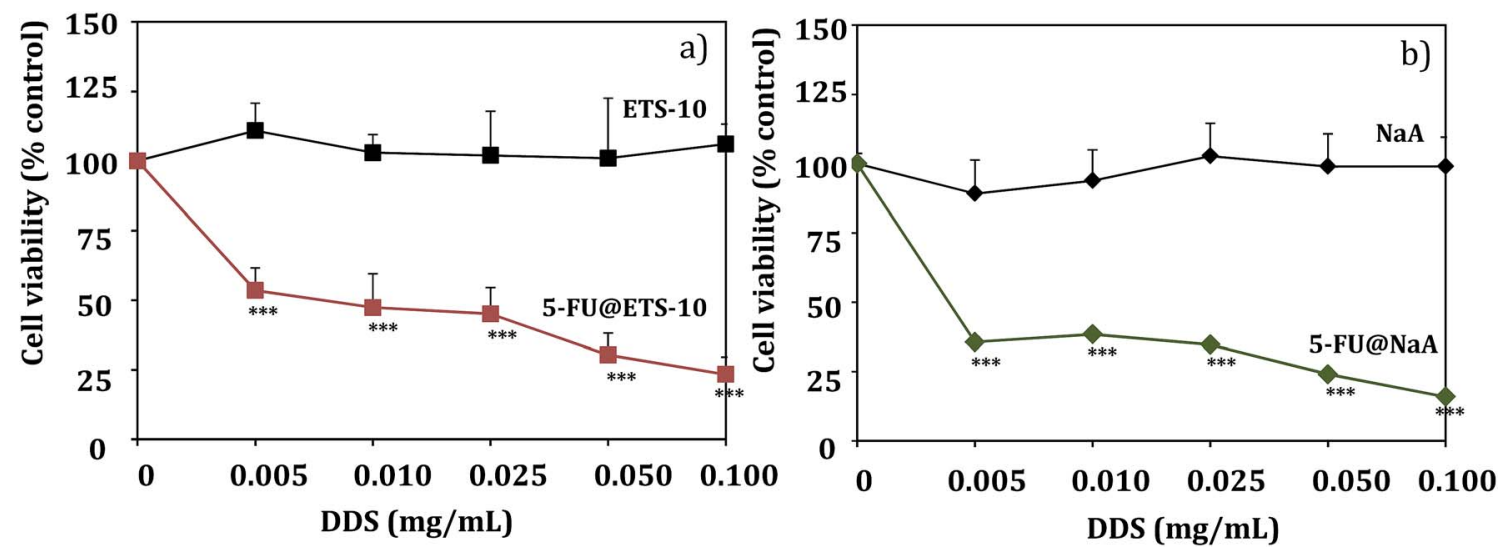

Fig. 7 Effect of ETS-10 (a) and NaA (b) hosts and DDS systems on RKO colon carcinoma cell viability. RKO cells were incubated with hosts and different DDS concentrations for $48 \mathrm{~h}$. Cell viability was measured by the SRB assay. Values are means \pm SD of three independent experiments, each performed in triplicate. ${ }^{*} p<0.05, * * * p<0.001$ compared to host alone. 
Table $3 \quad I C_{50}$ values for RKO and HCT-15 cell viability with 5-FU and DDS systems containing 5-FU

\begin{tabular}{|c|c|c|c|c|}
\hline \multirow[b]{2}{*}{ Cell line } & \multicolumn{2}{|l|}{ RKO } & \multicolumn{2}{|l|}{ HCT-15 } \\
\hline & $\mathrm{IC}_{50}(\mathrm{mM})$ & Potentiation & $\mathrm{IC}_{50}(\mathrm{mM})$ & Potentiation \\
\hline 5-FU & 0.13 & - & 0.61 & - \\
\hline 5-FU@NaY & 0.02 & 6.5 & 0.10 & 6.1 \\
\hline 5-FU@HZSM5 & 0.02 & 6.5 & 0.09 & 6.8 \\
\hline 5-FU@NaZSM5 & 0.08 & 1.6 & 0.20 & 3.1 \\
\hline 5-FU@NaA & 0.11 & 1.2 & 0.11 & 5.5 \\
\hline 5-FU@ETS-10 & 0.02 & 6.5 & 0.12 & 5.1 \\
\hline 5-FU@LTL ${ }^{a}$ & 0.03 & 4.3 & 0.31 & 1.9 \\
\hline
\end{tabular}

systems. ${ }^{41}$ However, the acidic surface characteristics could be also associated with some toxicity for specific cells. In fact, we showed that NaY zeolite induces toxicity in glioblastoma cells in all range of concentrations studied, but NaMOR zeolite did not show any toxicity to these cells. These results confirm that the zeolite toxicity is dependent on the cell type and the properties of the carrier structure. Also, in the same study, our results show that the DDS prepared with NaMOR are capable of reducing tumor size, using the in vivo chick chorioallantoic membrane (CAM) model. ${ }^{21}$

From Fig. 7, we can also see that there is an evident reduction in cell viability with 5 -FU containing DDS, compared to ETS-10 or NaA (controls), with increasing concentrations of 5FU in both DDS, for RKO cells.

Table 3 shows the $\mathrm{IC}_{50}$ values for RKO and HCT-15 cell viability after treatment with the DDS systems, compared with the drug alone.

It is clear from the results that there is a potentiation of the 5FU when is encapsulated into the silica microporous structures in both colorectal cancer cell lines. This potentiation is dependent on the capacity of 5-FU loading, as well as on the porous framework of the hosts. For RKO cells, there is an increase in efficiency of the drug between 1.2 and 6.5-fold. The highest potentiation (6.5-fold) was obtained with the 3D structures, (ETS-10 and NaY, large pores) and HZSM5 (medium pores) hosts, which correspond to 5-FU assay concentrations of $0.02 \mathrm{mM}$.

Concerning ZSM5 structure, the reduction in pore aperture in NaZSM5 decreases 5-FU potentiation in about 4 -fold when compared to 5-FU@HZSM5. The lowest potentiation obtained was for NaA host (1.2-fold), which contains $0.11 \mathrm{mM}$ of 5 -FU. Likewise, treatment of HCT-15 cells with the encapsulated 5-FU

Table $4 \quad I_{50}$ values for MDA-MB-468 cell viability for 5-FU and DDS systems containing 5-FU

\begin{tabular}{lll}
\hline & \multicolumn{2}{c}{ MDA-MB-468 } \\
\cline { 2 - 3 } Cell line & $\mathrm{IC}_{50}(\mathrm{mM})$ & Potentiation \\
\hline 5-FU & 3.80 & - \\
5-FU@NaY & 0.38 & 10.0 \\
5-FU@NaA & 0.37 & 10.2 \\
5-FU@ETS-10 & 0.19 & 19.9
\end{tabular}

resulted in a potentiation of the effect of the drug from 3.1 to 6.8-fold, corresponding to 5-FU assay concentrations of 0.20 and $0.09 \mathrm{mM}$, respectively. For this cell line, the 3D structures seem to favor the potentiation of the drug, rather than the loading of 5-FU in the hosts.

The viability assays were also performed on MDA-MB-468 human breast cancer cells with the DDS based on NaY and ETS10 (large pores) and compared with $\mathrm{NaA}$ (small pore). In addition, these hosts are not toxic for this cell line (Fig. S4, ESI $\dagger$ ) and the DDS based in these hosts were very efficient in the decrease of the cell viability (Table 4). Importantly, inclusion of 5-FU in the DDS, increased substantially the sensitivity of the breast cancer cells to 5-FU, which are more resistant than the colon cancer cells.

For MDA-MB-468 cells, the best DDS was obtained with ETS10 with higher 5-FU loading. The potentiation obtained is double compared to the zeolite systems, which display the same potentiation among them, despite different loadings (Table 1).

The potential of these host structures will depend on the design and delivery route to be used. While smaller particles ( $<100 \mathrm{~nm}$, LTL zeolite) would be suitable for systemic administration, e.g. intra venous or inhalation delivery, larger particles (>100 nm, NaY, NaA and ZSM5 zeolites, and ETS-10) will have potential for topical delivery (Fig. 1). Besides systemic treatment, 5-FU is also used topically for the treatment of non-melanoma skin cancer (e.g. superficial basal cell carcinoma) or even other skin pathological conditions such as actinic or solar keratosis. ${ }^{\mathbf{4 2 , 4 3}}$

\section{Conclusions}

The hosts selected for this work show potential to be used in the future design and development of DDS for biomedical applications. The silica microporous structures were selected due to the combination of non-cytotoxic effects to the cells, wide and accessible pore expected to be favorable for enhancement of the activity of 5-fluorouracil (5-FU). 5-FU was successfully loaded into the host structures and 5-FU loading was found to be highest in 3D large pores (NaY and ETS-10) followed by ZSM5 (3D, medium pore) and $\mathrm{NaA}(3 \mathrm{D}$, small pore). All structures are not toxic to the colon and breast cancer cell lines studied and they preserved the integrity of 5-FU even at lower $\mathrm{pH}$, before the contact with the cells. Moreover, 5-FU loaded into the host structures can be at least six times more effective in colon cancer cell death induction than the free 5-FU administered in vitro (5-FU@NaY and 5-FU@HZSM5 systems) and twenty times more effective for the breast cancer cells (5-FU@ETS-10).

\section{Acknowledgements}

N. V., F. M. S. and R. A. are recipients of PhD fellowships (SFRH/ BD/97797/2013, SFRH/BD/87139/2012 and SFRH/BD/98002/ 2013) from Foundation for Science and Technology (FCT, Portugal). MS also acknowledges FCT for a post-doc grant (SFRH/ BPD/65978/2009). This work has been developed under the scope of the project NORTE-01-0145-FEDER-000013 and the project BioTecNorte (operation NORTE-01-0145-FEDER000004), supported by the Northern Portugal Regional Operational Programme (NORTE 2020), under the Portugal 2020 
Partnership Agreement, through the European Regional Development Fund (FEDER). This work also has been funded by national funds (FCT), through the projects: Centre of Chemistry (UID/QUI/00686/2013 and UID/QUI/0686/2016); CICECO (PEstC/CTM/LA0011/2013，F-COMP-01-0124-FEDER-037271); LSRE/ LCM (POCI-01-0145-FEDER-006984) and ICVS/3B's (POCI-010145-FEDER-007038).

\section{Notes and references}

1 Y. Zhang, H. F. Chan and K. W. Leong, Adv. Drug Delivery Rev., 2013, 65, 104-120.

2 N. A. Peppas, Adv. Drug Delivery Rev., 2013, 65, 5-9.

3 C. S. Kim, G. Y. Tonga, D. Solfiell and V. M. Rotello, Adv. Drug Delivery Rev., 2013, 65, 93-99.

4 N. Vilaça, R. Amorim, A. F. Machado, P. Parpot, M. F. R. Pereira, M. Sardo, J. Rocha, A. M. Fonseca, I. C. Neves and F. Baltazar, Colloids Surf., B, 2013, 112, 237-244.

5 I. Braschi, S. Blasioli, L. Gigli, C. E. Gessa, A. Alberti and A. Martucci, J. Hazard. Mater., 2010, 178(2010), 218-225.

6 H. Zhang, Y. Kim and P. K. Dutta, Microporous Mesoporous Mater., 2006, 88, 312-318.

7 M. Norek, I. C. Neves and J. A. Peters, Inorg. Chem., 2007, 46, 6190-6196.

8 W.-S. Li, Z.-F. Li, F.-Y. Jing, X.-G. Yang, X.-J. Li, F.-K. Pei, X.-X. Wang and H. Lei, Acta Chim. Sinica, 2007, 65, 20292033.

9 C. Platas-Iglesias, L. V. Elst, W. Zhou, R. N. Muller, C. F. G. C. Geraldes, T. Maschmeyer and J. A. Peters, Chem.-Eur. J., 2002, 8, 5121-5131.

10 I. Braschi, G. Gatti, G. Paul, C. E. Gessa, M. Cossi and L. Marchese, Langmuir, 2010, 26, 9524-9532.

11 M. L. Pinto, A. C. Fernandes, F. Antunes, J. Pires and J. Rocha, Microporous Mesoporous Mater., 2016, 229, 83-89.

12 M. L. Pinto, J. Rocha, J. R. B. Gomes and J. Pires, J. Am. Chem. Soc., 2011, 133, 6396-6402.

13 M. L. Pinto, A. C. Fernandes, J. Rocha, A. Ferreira, F. Antunes and J. Pires, J. Mater. Chem. B, 2014, 2, 224-230.

14 D. B. Longley, D. P. Harkin and P. G. Johnston, Nat. Rev. Cancer, 2003, 3, 330-338.

15 N. Zhang, Y. Yin, S.-J. Xu and W. S. Chen, Molecules, 2008, 13, 1551-1569.

16 K. Yoneda, T. Yamamoto, E. Ueta and T. Osaki, Cancer Lett., 1999, 137, 17-25.

17 J. L. Arias, M. A. Ruiz, M. López-Viota and A. V. Delgado, Colloids Surf., B, 2008, 62, 64-70.

18 J. L. Arias, M. A. Ruiz, M. López-Viota, A. V. Delgado and M. A. Ruiz, Colloids Surf., B, 2010, 77, 111-116.

19 J. Rocha, A. Ferreira, Z. Lin and M. W. Anderson, Microporous Mesoporous Mater., 1998, 23, 253-263.

20 B. Silva, H. Figueiredo, O. S. G. P. Soares, M. F. R. Pereira, J. L. Figueiredo, A. E. Lewandowska, M. A. Banares, I. C. Neves and T. Tavares, Appl. Catal., B, 2012, 117, 406-413.

21 O. Martinho, N. Vilaça, P. J. G. Castro, R. Amorim, A. M. Fonseca, F. Baltazar, R. M. Reis and I. C. Neves, RSC Adv., 2015, 5, 28219-28227.
22 N. Vilaça, F. Morais-Santos, A. F. Machado, A. Sirkecioğlu, M. F. R. Pereira, M. Sardo, J. Rocha, P. Parpot, A. M. Fonseca, F. Baltazar and I. C. Neves, J. Phys. Chem. C, 2015, 119, 3589-3595.

23 K. A. Fisher, K. D. Huddersman and M. J. Taylor, Chem.-Eur. J., 2003, 9, 5873-5878.

24 Database of Zeolite Structures from the International Zeolite Association, http:/www.iza-structure.org/databases/, accessed in 10 January 2017.

25 M. R. C. Marques, R. Loebenberg and M. Almukainzi, Dissolution Technol., 2011, 18, 15-28.

26 R. Amorim, N. Vilaça, O. Martinho, R. M. Reis, M. Sardo, J. Rocha, A. M. Fonseca, F. Baltazar and I. C. Neves, J. Phys. Chem. C, 2012, 116, 25642-25650.

27 S. Farquharson, A. Gift, C. Shende, F. Inscore, B. Ordway, C. Farquharson and J. Murren, Molecules, 2008, 13, 26082627.

28 A. Datt, E. A. Burns, N. A. Dhuna and S. C. Larsen, Microporous Mesoporous Mater., 2013, 167, 182-187.

29 L. Maggini, I. Cabrera, A. Ruiz-Carretero, E. A. Prasetyanto, E. Robinet and L. De Cola, Nanoscale, 2016, 8, 7240-7247.

30 R. Mellaerts, R. Mols, J. A. G. Jammaer, C. A. Aerts, P. Annaert, J. Van Humbeeck, G. Van den Mooter, P. Augustijns and J. A. Martens, Eur. J. Pharm. Biopharm., 2008, 69, 223-230.

31 E. Verraedt, M. Pendela, E. Adams, J. Hoogmartens and J. A. Martens, J. Controlled Release, 2010, 142, 47-52.

32 P. Costa and J. M. S. Lobo, Eur. J. Pharm. Sci., 2001, 13, 123133.

33 S. Dash, P. N. Murthy, L. Nath and P. Chowdhury, Acta Pol. Pharm., 2010, 67, 217-233.

34 I. K. Biernacka, P. Parpot, C. Oliveira, A. R. Silva, M. J. Alves, A. M. Fonseca and I. C. Neves, J. Phys. Chem. C, 2014, 118, 19042-19050.

35 K. Thelen, K. Coboeken, S. Willmann, J. B. Dressman and J. Lippert, J. Pharm. Sci., 2012, 101, 1267-1280.

36 M. Guo, E. A. Pidko, F. Fan, Z. Feng, J. P. Hofmann, B. M. Weckhuysen, E. J. M. Hensen and C. Li, J. Phys. Chem. C, 2012, 116, 17124-17133.

37 G. C. Ghesti, J. L. Macedo, V. C. I. Parente, J. A. Dias and S. C. L. Dias, Microporous Mesoporous Mater., 2007, 100, 27-34.

38 M. W. Anderson, J. Rocha, Z. Lin, A. Philippou, I. Orion and A. Ferreira, Microporous Mater., 1996, 6, 195-204.

39 Z. Lin, J. Rocha, A. Ferreira and M. W. Anderson, Colloids Surf., A, 2001, 179, 133-138.

40 N. Vilaça, R. Amorim, O. Martinho, R. M. Reis, F. Baltazar, A. M. Fonseca and I. C. Neves, J. Mater. Sci., 2011, 46, 7511-7516.

41 A. Petushkov, N. Ndiege, A. K. Salem and S. C. Larsen, in Advances in Molecular Toxicology, ed. J. C. Fishbein, Elsevier, 2010, vol. 4, ch. 7, pp. 223-266.

42 P. Herranz, C. Morton, T. Dirschka, R. R. Azeredo and R. Roldán-Marín, J. Cutaneous Med. Surg., 2016, 20, 555-561.

43 B. T. Nguyen, S. D. Gan, N. Konnikov and C. A. Liang, J. Am. Acad. Dermatol., 2015, 72, 558-560. 